\title{
A type of polycarboxylate superplasticizer used in high performance self-compacting concrete
}

\author{
Xing $\mathrm{Li}^{1, \mathrm{a}}$, Rixu Zhao ${ }^{1}$, Wen $\mathrm{Yang}^{1}$, Yao Bi ${ }^{1}$, Minghua Yuan ${ }^{1}$, Shaofeng Wang ${ }^{1}$ \\ ${ }^{1}$ China Construction Ready Mixed Concrete Co. Ltd, Wuhan 430205, China,
}

aleexingbridge@yeah.net

Keywords: self-compacting concrete, high performance, polycarboxylate superplasticizer;

\begin{abstract}
In this study, a kind of polycarboxylate superplasticizer used in high performance self-compacting concrete was synthesised. The examined properties included workability, T500, compressive strength,etc. Workability of the fresh concrete was determined by using both the slump-flow test. The results showed that it was possible to successfully use this polycarboxylate superplasticizer in producing SCC.
\end{abstract}

\section{Introduction}

Self compacting concrete is a type of concrete that is highly fluid allowing it to self-level, penetrate into complicated areas and formwork, through complex reinforcement and much more[1]. Despite its increased fluidity, self compacting concrete maintains the high quality demanded by today's building industry, presenting both flexibility as well as incredible strength. Its flexibility lies in the fact that there are multiple admixtures that can be added when designing the mix to create a final product that is suitable for the end result.

Many case studies of applications of self-compacting concrete (SCC)[2]have been analysed from 1993 to nowadays, increasingly widespread use of SCC in many countries. They were selected for analysis on the basis of including details of concrete formulations and properties. The ranges of properties, component materials and mix proportions show the diverse nature of SCC, and confirm that it should be considered as a family of mixes suitable for a wide range of applications with widely varying requirements[3].

High water reducer - superplasticizer. This is an admixture that is used in all types of self compacting concrete because it is what gives it its flowability. Essentially, this admixture reduces the quantity of water needed to achieve the same consistency as traditional concrete meaning that if the same quantity of water is used then the resulting material will be much more fluid and easy to work with. Therefore, polycarboxylate superplasticizers are sidely used in self-compacting concrete.

\section{Experimental}

\subsection{Chemicals and Equipment.}

Prenyl alcohol ethoxylates (TPEG, Taijie Chemical Co. LTD), Acrylic acid (AA,Wuhan Zhonghua Yongye Chemical Co. LTD), Ammonium persulfate (APS, Wuhan chemical Co. LTD), Chain transfer agent (TGA, Changzhou Yurong Chemical Co.LTD) , sodium hydroxide(NaOH), HuaXin cement,P.O42.5, WuGang II flyash, WuXin S95 silica fume. Cement paste mixer,NJ-160A,WuXi JianYi equipment Co. LTD ; Single horizontal-axis laboratory concrete mixer,HJW-60, ShenYang JuLin equipment Co. LTD. 


\subsection{Synthesis Process.}

Put water and TPEG into a flask, and stirried until the end of experiment; wait until TPEG dissolved, and dripped the mixture of APS and AA , separately dripped TGA solution; keep stirring for certain hours, then added the sodium hydroxide and water, and adjusted $\mathrm{pH}$ of the new product about 7; The new product would been gotten and its solid content was $40 \%$.

\subsection{Measurement.}

The fluidity of cement slurry was tested according to Chinese Standard (GB/8077-2000). The water-cement ratio is 0.29 ,PCs dosage is $0.13 \%$.

\section{Results and Discussion}

\subsection{The dose of use in various types of concrete}

Table.1 Mix ratio of concrete

\begin{tabular}{ccccccccc}
\hline & & \multicolumn{2}{c}{ Mineral } & Silica & & & \\
strength-grade & cement & ash & powder & sand & stone & water & dose\% \\
\hline C70 & 390 & 100 & 85 & 45 & 660 & 990 & 135 & 2.2 \\
C80 & 400 & 50 & 140 & 50 & 660 & 980 & 130 & 2.4 \\
C100 & 450 & 50 & 115 & 65 & 650 & 960 & 130 & 2.6 \\
\hline
\end{tabular}

Table.2 Fluidity of cement paste with different superplasticizer

\begin{tabular}{ccccc}
\hline strength-grade & superplasticizer & 0h mm & $1 \mathrm{~h} \mathrm{~mm}$ & $3 \mathrm{~h} \mathrm{~mm}$ \\
\hline \multirow{2}{*}{ C70 } & Ordinary & $260 / 700$ & $235 / 595$ & $215 / 490$ \\
& our & $260 / 710$ & $260 / 690$ & $260 / 690$ \\
\hline \multirow{2}{*}{ C80 } & Ordinary & $265 / 720$ & $230 / 580$ & $210 / 500$ \\
& our & $260 / 730$ & $255 / 720$ & $265 / 735$ \\
\hline \multirow{2}{*}{ C100 } & Ordinary & $260 / 725$ & $235 / 620$ & $230 / 510$ \\
& our & $260 / 735$ & $260 / 710$ & $265 / 720$ \\
\hline
\end{tabular}

Table. 2 shows that our is superior to the ordinary superplasticizer, self-compacting concrete has better fluidity when the same dose of admiture is added. 

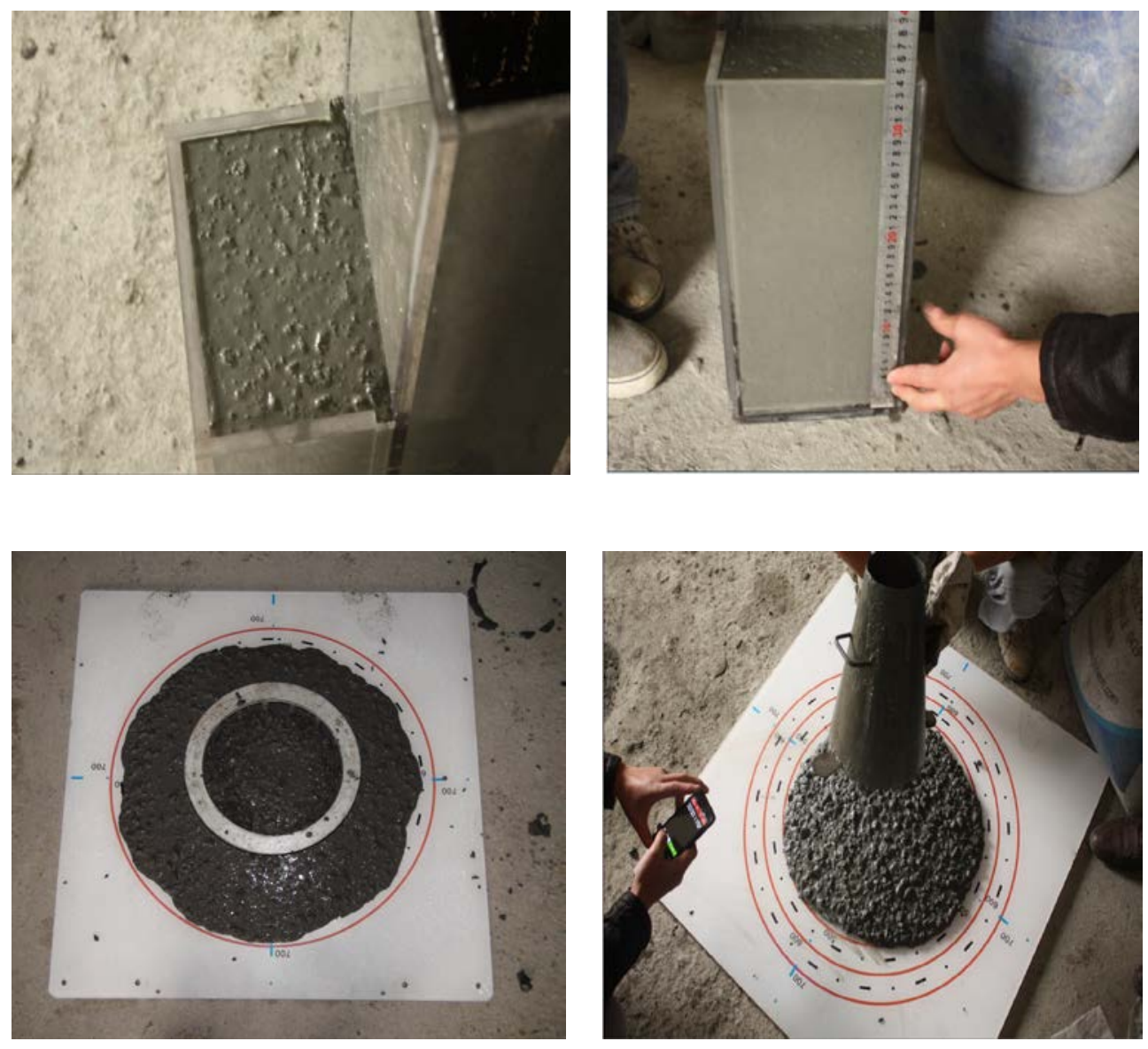

Fig3. Pictures of the test

Table.3 Effect on C70 concrete

\begin{tabular}{|c|c|c|c|c|c|c|c|c|}
\hline types & & time/s & $\mathrm{T}_{500} / \mathrm{s}$ & slump/ & J-loop & unit weight & $\begin{array}{c}\mathrm{U} \\
\text { box/m }\end{array}$ & $\begin{array}{l}\text { rate } \\
\text { of }\end{array}$ \\
\hline \multirow{3}{*}{ our } & & & & $265 / 72$ & & \multirow{3}{*}{2410} & & \\
\hline & $0 \mathrm{~h}$ & 5.71 & 4.5 & 0 & 690 & & 335 & $7.8 \%$ \\
\hline & $3 \mathrm{~h}$ & 5.55 & 4.0 & $\begin{array}{c}270 / 73 \\
0\end{array}$ & 685 & & 340 & $7.4 \%$ \\
\hline \multirow{2}{*}{ ordinary } & $0 \mathrm{~h}$ & 4.92 & 4.8 & $\begin{array}{c}265 / 73 \\
0\end{array}$ & 700 & \multirow{2}{*}{2410} & 340 & $7.9 \%$ \\
\hline & $3 \mathrm{~h}$ & 5.73 & 5.2 & $\begin{array}{c}265 / 70 \\
0\end{array}$ & 670 & & 335 & $7.5 \%$ \\
\hline
\end{tabular}




\begin{tabular}{|c|c|c|c|c|c|c|c|c|}
\hline \multirow{3}{*}{ types } & & \multirow{3}{*}{ time/s } & \multirow{3}{*}{$\mathrm{T}_{500} / \mathrm{s}$} & \multirow{3}{*}{$\begin{array}{l}\text { slump/ } \\
\text { mm }\end{array}$} & \multirow{3}{*}{$\begin{array}{l}\text { J-loop } \\
\text { /mm }\end{array}$} & \multirow{3}{*}{$\begin{array}{c}\text { unit } \\
\text { weight } \\
\text { Kg/m3 }\end{array}$} & \multirow{3}{*}{$\mathrm{U}$ box/mm } & \multirow{3}{*}{$\begin{array}{c}\text { rate } \\
\text { of } \\
\text { segreg } \\
\text { ation }\end{array}$} \\
\hline & & & & & & & & \\
\hline & & & & & & & & \\
\hline \multirow[b]{2}{*}{ our } & 初始 & 5.33 & 4.4 & $265 / 730$ & 700 & \multirow{2}{*}{2420} & 340 & $7.6 \%$ \\
\hline & 3h & 5.71 & 3.8 & $270 / 695$ & 695 & & 340 & $7.0 \%$ \\
\hline \multirow{3}{*}{ ordinary } & 初始 & 4.22 & 5.0 & $265 / 720$ & 690 & \multirow{3}{*}{2420} & 340 & $8.2 \%$ \\
\hline & 3h & 5.87 & 6.8 & $260 / 700$ & 680 & & 330 & $7.1 \%$ \\
\hline & 3h & 7.06 & 8.7 & $260 / 705$ & 685 & & 320 & $6.1 \%$ \\
\hline
\end{tabular}

T500、J-loop、U-box 、 unit weight and rate of segregation are tested in in various types of strength-grade concrete, Table1-4 show that our performances are better than ordinary superplasticizers.

Table.5 Effect on strength of C70-C10

\begin{tabular}{|c|c|c|c|c|c|}
\hline strength grade & types & $\begin{array}{c}\text { initial setting } \\
\text { time } / \mathrm{h}\end{array}$ & $\begin{array}{c}\text { final setting } \\
\text { time } / \mathrm{h}\end{array}$ & $\mathrm{R}_{7} / \mathrm{MPa}$ & $\mathrm{R}_{28} / \mathrm{MPa}$ \\
\hline & our & 12 & 14.5 & 73.5 & 85.1 \\
\hline \multirow[t]{3}{*}{ C70 } & ordinary & 11.5 & 14 & 70.2 & 81.2 \\
\hline & others & 11.5 & 14.5 & 69.5 & 80.1 \\
\hline & ZJSS-II & 13.0 & 15 & 83.3 & 95.6 \\
\hline \multirow[t]{3}{*}{ C80 } & ordinary & 12.5 & 15 & 78.6 & 92.3 \\
\hline & others & 12.5 & 14.5 & 77.2 & 90.5 \\
\hline & ZJSS-II & 13.5 & 15 & 102.5 & 123.2 \\
\hline \multirow[t]{2}{*}{ C100 } & ordinary & 13.5 & 15 & 98.3 & 121.4 \\
\hline & others & 13.0 & 14.5 & 97.6 & 120.7 \\
\hline
\end{tabular}

Table5 shows that our product is superior than ordinary products in the market . The strength of 7days and 28days used with our superplasticizer is a little higher than ordinary superplasticizers .

\section{Conclusion}

T500、J-loop、U-box 、 unit weight and rate of segregation are tested in in various types of strength-grade concrete, the results show that our performances are better than ordinary 
superplasticizers.By discussing various factors that impact the performance of PCs, we confirm a kind of polycarboxylate superplasticizer used in high performance self-compacting concrete.

\section{References}

[1] Alireza K, John L et al. Effect of molecular architecture of polycarboxylate ethers on plasticizing performance in alkali-activated slag paste [J]. J Mater Sci, 2014(49):2761-2772.

[2] Alone M, Palacios M, et al. Compatibility between polycarboxylate-based admixtures and blended-cement pastes [J]. Cement and Concrete Composites, 2013, (35):151-162.

[3] Yamada K, Takahashi T, Hanehara S, et al. Effects of the Chemical Structure on the Properties of Polycarboxylate-type Superplasticizer[J]. Cement and Concrete Research, 2000, 30(2): 197-207. 